\title{
Genetic polymorphisms and haplotype of hormone-related genes are associated with the risk of breast cancer in Chinese women
}

\author{
Z. Pan ${ }^{1,2}$, Z. Fu ${ }^{3}$, Q. Song ${ }^{1}$, W. Cao ${ }^{4}$, W. Cheng ${ }^{1}$ and X. Xut ${ }^{1,2}$ \\ ${ }^{1}$ Department of Clinical Laboratory, Hangzhou, China \\ ${ }^{2}$ Key Laboratory Diagnosis and Treatment Technology on Thoracic Oncology, \\ Hangzhou, China \\ ${ }^{3}$ Department of Colorectal Cancer Surgery, Hangzhou, China \\ ${ }^{4}$ Department of Medical Oncology, Zhejiang Cancer Hospital, Hangzhou, China \\ Corresponding author: $\mathrm{X} . \mathrm{Xu}$ \\ E-mail: zjhzxxh@163.com \\ Genet. Mol. Res. 15 (2): gmr.15028640 \\ Received March 23, 2016 \\ Accepted April 11, 2016 \\ Published May 13, 2016 \\ DOI http://dx.doi.org/10.4238/gmr.15028640
}

\begin{abstract}
Sex hormones play important roles in breast cancer (BC) development. This study investigated associations between BC risk and hormone-related gene variants in Chinese women. In a cohort of 336 patients with histopathologically confirmed BC and 390 age-matched controls, we genotyped seven single nucleotide polymorphisms (SNPs) in five hormone-related genes: estrogen receptor- $\alpha$ (ESR1), aromatase (CYP19), catechol-O-methyl transferase (COMT), sex hormonebinding globulin $(S H B G)$, and glutathione $S$-transferase (GSTP1). Among these seven SNPs, the SNPs in GSTP1 rs1695 [A/G; odds ratio (OR): 1.68; 95\% confidence interval (CI): 1.23-2.30] and ESR1 rs2046210 (C/T; OR: 1.39; 95\%CI = 1.02-1.91) were associated with an increased risk among heterozygote carriers. Homozygotes of minor alleles of CYP19 rs10046 (CC) were associated with a reduced risk of BC with OR: $0.61(95 \% \mathrm{CI}=0.39-0.95)$. In addition, a stratified analysis by menopausal status indicated that the association of the
\end{abstract}


CYP19 polymorphisms (rs10046 and rs700519) with BC risk was mainly evident in premenopausal women, and the association of CYP19 rs700519 with $\mathrm{BC}$ risk was significant in women less than 50 years old. Haplotype analysis identified 15 common haplotypes $(>1 \%)$. The haplotype TGGGGTC was significantly associated with $\mathrm{BC}$ risk compared with the reference haplotype CGAGGTC (OR $>1000, \mathrm{P}<0.0001)$. Our data demonstrate that these ESR1, GSTP1, and CYP19 polymorphisms are associated with risk of $\mathrm{BC}$, and the risk haplotype TGGGGTC could help to identify populations with high susceptibility to $\mathrm{BC}$ in Chinese women.

Key words: Breast cancer; Hormone-related gene; Genetic variants; Haplotype; Association analysis

\section{INTRODUCTION}

Endogenous sex steroids have been shown epidemiologically to be associated with breast cancer (BC) development (Chen, 2008; Key et al., 2015). For example, high levels of circulating estradiol and estrone are associated with increased BC in postmenopausal women (Key et al., 2002; Lukanova et al., 2004; Missmer et al., 2004; Kaaks et al., 2005). BC risk is also indirectly linked to premenopausal hormone levels by epidemiological studies (Pike et al., 1983).

Although many epidemiological studies have evaluated the potential role of polymorphisms in estrogen metabolizing genes in $\mathrm{BC}$ risk, the overall results remain inconsistent. We selected several genes involved in estrogen synthesis and metabolism, including COMT (catechol-O-methyl transferase), CYP19 (aromatase), ESR1 (estrogen receptor- $\alpha$ ), GSTP1 (glutathione S-transferase P), and $S H B G$ (sex hormone-binding globulin). COMT, an important estrogen-metabolizing enzyme, has a functional single nucleotide polymorphism (SNP) rs4680 (Val158Met), which results in a valine-to-methionine amino acid substitution and is associated with decreased activity of the COMT enzyme (Dawling et al., 2001). The CYP19 gene encodes aromatase, which has two SNPs: rs700519, a non-synonymous coding SNP (Arg264Cys) in exon 7, and rs10046, located in the 3'UTR region of the CYP19 gene. ESR1 encodes an estrogen receptor with two SNPs: the rs2046210 SNP, which is located $29 \mathrm{~kb}$ upstream of the first untranslated exon, and the rs9383951 SNP, which is located in ESR1 intron 5. The GSTP1 SNP rs 1695 (Ile105Val) $\mathrm{G}$ allele has been demonstrated to exhibit abnormal catalytic enzyme activity (Zimniak et al., 1994). A non-synonymous SNP in exon 8 of the $S H B G$ gene results in an amino acid substitution of asparagine for aspartic acid, and the asparagine $(\mathrm{N})$ allele is associated with elevated levels of SHBG in postmenopausal women (Haiman et al., 2005). Functionally relevant polymorphisms in these hormone-related genes may alter hormone levels and affect the risk of BC. Candidate polymorphisms selected in our study were associated with BC risk in some, but not all, studies. Therefore, we selected these polymorphisms in hormone-related genes to assess whether these variants are associated with the risk of $\mathrm{BC}$ risk in Chinese women.

\section{MATERIAL AND METHODS}

\section{Study population}

This study was approved by the Ethics Committee of Zhejiang Cancer Hospital. We 
recruited 336 women with pathologically confirmed BC (mean age: 46 years; range: 27-84 years) in the Zhejiang Cancer Hospital during May 2011 and September 2012. We took detailed clinicopathological information, including tumor size, histological grade, and lymph node involvement, as well as estrogen receptor (ER), progesterone receptor, and human epidermal growth factor receptor 2 statuses from patients' medical records (Table 1). As controls, we randomly selected 390 age-matched ( \pm 5 years) cancer-free women from the same residential areas.

Table 1. Clinicopathological characteristics of breast cancer patients.

\begin{tabular}{|c|c|c|}
\hline Characteristics & Cases (\%) & Controls (\%) \\
\hline \multicolumn{3}{|l|}{ Age (years) } \\
\hline$\leq 50$ & $200(59.5 \%)$ & $236(60.5 \%)$ \\
\hline$>50$ & $136(40.5 \%)$ & $154(39.5 \%)$ \\
\hline \multicolumn{3}{|l|}{ Menopausal status } \\
\hline Premenopausal & $203(60.4 \%)$ & \\
\hline Postmenopausal & $133(39.6 \%)$ & \\
\hline \multicolumn{3}{|l|}{ Tumor size $(\mathrm{cm})$} \\
\hline$\leq 2$ & $59(17.6 \%)$ & \\
\hline$>2$ & $238(70.8 \%)$ & \\
\hline Missing & $39(11.6 \%)$ & \\
\hline \multicolumn{3}{|l|}{ Histological grade } \\
\hline $\mathrm{I}+\mathrm{II}$ & $137(40.8 \%)$ & \\
\hline III & $82(24.4 \%)$ & \\
\hline Missing & $117(34.8 \%)$ & \\
\hline \multicolumn{3}{|c|}{ Lymph node status } \\
\hline Negative & $116(34.5 \%)$ & \\
\hline Positive & $213(63.4 \%)$ & \\
\hline Missing & $7(2.1 \%)$ & \\
\hline \multicolumn{3}{|l|}{ ER status } \\
\hline Negative & $114(33.9 \%)$ & \\
\hline Positive & $211(62.8 \%)$ & \\
\hline Missing & $11(3.3 \%)$ & \\
\hline \multicolumn{3}{|l|}{ PR status } \\
\hline Negative & $135(40.2 \%)$ & \\
\hline Positive & $190(56.5 \%)$ & \\
\hline Missing & $11(3.3 \%)$ & \\
\hline \multicolumn{3}{|l|}{ HER2 status } \\
\hline Negative & $201(59.8 \%)$ & \\
\hline Positive & $114(33.9 \%)$ & \\
\hline Missing & $21(6.3 \%)$ & \\
\hline
\end{tabular}

Missing: the number (\%) of cases for which the corresponding information was not available.

\section{DNA extraction and genotyping}

Genomic DNA was extracted from peripheral blood samples using a blood genomic DNA extraction kit (Xinjin Genetech Ltd., Hangzhou, China) according to the manufacturer protocol. We selected seven SNPs for genotyping as follows: ESR1 rs2046210 and rs9383951, CYP19 rs10046 and rs700519, COMT rs4680, SHBG rs6259, and GSTP1 rs1695. Genotyping was performed with the iPLEX MassARRAY ${ }^{\circledR}$ platform (Sequenom, San Diego, CA, USA) with an allele-specific, matrix-assisted, laser desorption/ionization time-of-flight assay (Jurinke et al., 2002). Primers for amplification and extension reactions were designed by Sequenom guidelines using MassARRAY ${ }^{\circledR}$ Assay Design software. Primers for COMT rs 4680 were 5'-CACCATCGAGATCAACCCCG-3' (F) and 5'-TTCCAGGTCTGACAACGGGT-3' (R); CYP19 rs10046: 5'-GACTTGTCCTTGCACCCAGA-3' (F) and 5'-GGCCACTGAGTGTTC 
ACTGT-3' (R); CYP19 rs700519: 5'-CAGCAAGGATTTGAAAGATGCCA-3' (F) and 5'-GTTCAGGTCAGTACCTCTGCT-3' (R); ESR1 rs2046210: 5'-CATCAGGGTGCCTCAA CTGT-3' (F) and 5'-TCCTCACACATACATACAGTCACA-3' (R); ESR1 rs9383951: 5'-AGT CACAGCCAGCTTACAGAG-3' (F) and 5'-AGGCTCTTTCCTCTCAGGTCA-3' (R); SHBG rs6259: 5'-ATGCCACCTTTGCACTACCT-3' (F) and 5'-TTGTGCCCAAAGGCCATTCA-3' (R); GSTP1 rs 1695: 5'-ATCCCCAGTGACTGTGTGTTG-3' (F) and 5'-AAGCCCCTTTCTTT GTTCAGC-3' (R). All procedures were performed following manufacturer instructions. The average genotype call rate for these SNPs was $>99 \%$; the concordance rate for all SNPs was $100 \%$.

\section{Statistical analysis}

Deviation from the Hardy-Weinberg equilibrium was examined in controls using the $\chi^{2}$ test. Logistic regression analysis was used for odds ratios (OR) and $95 \%$ confidence intervals (CIs) for genotype case-control associations and haplotype association analyses. The most common haplotype was selected as the reference. $\mathrm{P}<0.05$ was considered significant. Associations of SNPs and patients' clinicopathological features were assessed using logistic regression analyses restricted to cases (case-only analyses). All statistical analyses were performed with SNPStats software (http://bioinfo.iconcologia.net/SNPstats) (Solé et al., 2006).

\section{RESULTS}

Study population characteristics were compared by case-control status, as shown in Table 1. The mean age of controls was similar to that of the $\mathrm{BC}$ patients.

Variant allele frequencies and association analysis are shown in Table 2. All SNP frequencies were in Hardy-Weinberg equilibrium among controls (data not shown). Increased $\mathrm{BC}$ risk was significantly associated with SNPs in GSTP1 rs1695 (OR: $1.65 ; 95 \% \mathrm{CI}=1.19$ 2.28) and ESR1 rs2046210 (OR: 1.43; 95\%CI = 1.03-1.99) among heterozygote carriers. Homozygotes of CYP19 (rs10046) minor alleles (CC) were associated with significantly reduced $\mathrm{BC}$ risk (OR: $0.61 ; 95 \% \mathrm{CI}=0.39-0.95)$. The remaining SNPs were not observed to be associated significantly with a risk of $\mathrm{BC}$.

To explore the potential role of these SNP genotypes in BC, we further analyzed the association of these genotypes with clinicopathological features of patients (Table 3). A stratified analysis by menopausal status indicated that rs 700519 and rs 10046 were mainly evident in premenopausal women $(\mathrm{OR}: 2.31 ; 95 \% \mathrm{CI}=1.37-3.91$ and $\mathrm{OR}: 1.68 ; 95 \% \mathrm{CI}=$ 1.04-2.70). An analysis by age group showed that the association between SNP rs700519 and $\mathrm{BC}$ was stronger in women under 50 years old. Further, the association between the SNPs rs700519 and rs10046 and BC risk according to the ER/progesterone receptor/ human epidermal growth factor receptor 2 (HER-2) status was also explored; no difference was found (data not shown). The SHBG, ESR1, COMT, and GSTP1 SNPs were not associated with other clinicopathological features (data not shown).

Fifteen haplotypes with a frequency greater than $1 \%$ were identified (Table 4 ). There was an overall haplotype effect when comparing cases to controls $(\mathrm{P}=0.0025)$. The haplotype TGGGGTC was associated with higher BC risk than the reference haplotype CGAGGTC (OR > 1000; P < 0.0001). Other haplotypes showed no association with $\mathrm{BC}$ risk. 
Table 2. Genotype frequencies in breast cancer patients and control group.

\begin{tabular}{|c|c|c|c|c|}
\hline Genotype & Controls $(\%) \mathrm{N}=392$ & Cases $(\%) \mathrm{N}=336$ & OR $(95 \% \mathrm{CI})$ & P value \\
\hline \multicolumn{5}{|l|}{ rs 2046210} \\
\hline $\mathrm{C} / \mathrm{C}$ & $146(37.4 \%)$ & $97(30 \%)$ & 1.00 & \\
\hline $\mathrm{C} / \mathrm{T}$ & $187(48 \%)$ & $178(55.1 \%)$ & $1.43(1.03-1.99)$ & 0.031 \\
\hline $\mathrm{T} / \mathrm{T}$ & $57(14.6 \%)$ & $48(14.9 \%)$ & $1.27(0.8-2.01)$ & 0.31 \\
\hline $\mathrm{C} / \mathrm{T}+\mathrm{T} / \mathrm{T}$ & $244(62.6 \%)$ & $226(70 \%)$ & $1.39(1.02-1.91)$ & 0.037 \\
\hline \multicolumn{5}{|l|}{ Rs9383951 } \\
\hline $\mathrm{G} / \mathrm{G}$ & $305(78.2 \%)$ & $272(83.4 \%)$ & 1.00 & \\
\hline $\mathrm{G} / \mathrm{C}$ & $75(19.2 \%)$ & $50(15.3 \%)$ & $0.75(0.5-1.11)$ & 0.146 \\
\hline $\mathrm{C} / \mathrm{C}$ & $10(2.6 \%)$ & $4(1.3 \%)$ & $0.45(0.14-1.45)$ & 0.168 \\
\hline $\mathrm{G} / \mathrm{C}+\mathrm{C} / \mathrm{C}$ & $85(21.8 \%)$ & $54(16.6 \%)$ & $0.71(0.49-1.04)$ & 0.078 \\
\hline \multicolumn{5}{|l|}{ Rs1695 } \\
\hline $\mathrm{A} / \mathrm{A}$ & $280(71.8 \%)$ & $194(60.2 \%)$ & 1.00 & \\
\hline $\mathrm{A} / \mathrm{G}$ & $100(25.6 \%)$ & $114(35.4 \%)$ & $1.65(1.19-2.28)$ & 0.0025 \\
\hline $\mathrm{G} / \mathrm{G}$ & $10(2.6 \%)$ & $14(4.3 \%)$ & $2.02(0.88-4.64)$ & 0.091 \\
\hline $\mathrm{A} / \mathrm{G}+\mathrm{G} / \mathrm{G}$ & $110(28.2 \%)$ & $128(39.8)$ & $1.68(1.23-2.30)$ & 0.0011 \\
\hline \multicolumn{5}{|l|}{ Rs6259 } \\
\hline $\mathrm{G} / \mathrm{G}$ & $265(68 \%)$ & $221(68 \%)$ & 1.00 & \\
\hline $\mathrm{G} / \mathrm{A}$ & $120(30.8 \%)$ & $98(30.1 \%)$ & $0.98(0.71-1.35)$ & 0.898 \\
\hline $\mathrm{A} / \mathrm{A}$ & $5(1.3 \%)$ & $6(1.9 \%)$ & $1.44(0.43-4.78)$ & 0.550 \\
\hline $\mathrm{G} / \mathrm{A}+\mathrm{A} / \mathrm{A}$ & $125(32 \%)$ & $104(32 \%)$ & $1.00(0.73-1.37)$ & 0.988 \\
\hline \multicolumn{5}{|l|}{ Rs4680 } \\
\hline $\mathrm{G} / \mathrm{G}$ & $221(57.3 \%)$ & $182(56.9 \%)$ & 1.00 & \\
\hline $\mathrm{A} / \mathrm{G}$ & $143(37 \%)$ & $119(37.2 \%)$ & $1.01(0.74-1.38)$ & 0.947 \\
\hline $\mathrm{A} / \mathrm{A}$ & $22(5.7 \%)$ & $19(5.9 \%)$ & $1.05(0.55-2.00)$ & 0.884 \\
\hline $\mathrm{A} / \mathrm{G}+\mathrm{A} / \mathrm{A}$ & $165(42.8 \%)$ & $138(43.1 \%)$ & $1.02(0.75-1.37)$ & 0.919 \\
\hline \multicolumn{5}{|l|}{ Rs10046 } \\
\hline $\mathrm{T} / \mathrm{T}$ & $111(28.3 \%)$ & $100(29.9 \%)$ & 1.00 & \\
\hline $\mathrm{T} / \mathrm{C}$ & $192(49 \%)$ & $185(55.4 \%)$ & $1.07(0.76-1.05)$ & 0.696 \\
\hline $\mathrm{C} / \mathrm{C}$ & $89(22.7 \%)$ & $49(14.7)$ & $0.61(0.39-0.95)$ & 0.028 \\
\hline $\mathrm{T} / \mathrm{C}+\mathrm{C} / \mathrm{C}$ & $281(71.7 \%)$ & $234(70.1)$ & $0.92(0.67-1.27)$ & 0.631 \\
\hline \multicolumn{5}{|l|}{ Rs700519 } \\
\hline $\mathrm{C} / \mathrm{C}$ & $289(74.1 \%)$ & $225(70.1 \%)$ & 1.00 & \\
\hline $\mathrm{T} / \mathrm{C}$ & $96(24.6 \%)$ & $87(27.1 \%)$ & $1.16(0.83-1.63)$ & 0.378 \\
\hline $\mathrm{T} / \mathrm{T}$ & $5(1.3 \%)$ & $9(2.8 \%)$ & $2.31(0.76-6.99)$ & 0.127 \\
\hline $\mathrm{T} / \mathrm{C}+\mathrm{T} / \mathrm{T}$ & $101(25.9 \%)$ & $96(29.9 \%)$ & $1.22(0.88-1.70)$ & 0.234 \\
\hline
\end{tabular}

Table 3. Subgroups analysis between SNPs and clinicopathological feature of breast cancer patients.

\begin{tabular}{|c|c|c|c|c|}
\hline \multirow[t]{2}{*}{ Characteristics } & \multicolumn{4}{|c|}{ rs 700519} \\
\hline & $\mathrm{C} / \mathrm{C}$ & $\mathrm{T} / \mathrm{C}$ & $\mathrm{T} / \mathrm{T}$ & $\mathrm{T} / \mathrm{C}+\mathrm{T} / \mathrm{T}$ \\
\hline \multicolumn{5}{|l|}{ Age onset } \\
\hline$>50 / \leq 50$ & $92 / 133$ & $24 / 63$ & $0 / 9$ & $24 / 72$ \\
\hline $\mathrm{OR}(95 \% \mathrm{CI})$ & 1.00 & $1.82(1.06-3.12)$ & NA & $2.08(1.22-3.54)$ \\
\hline P value & & 0.029 & 0.013 & 0.006 \\
\hline \multicolumn{5}{|l|}{ Menopause } \\
\hline Post/pre & $101 / 124$ & $25 / 62$ & $0 / 9$ & $25 / 71$ \\
\hline OR $(95 \% \mathrm{CI})$ & 1.00 & $2.02(1.18-3.44)$ & NA (0-NA) & $2.31(1.37-3.91)$ \\
\hline \multirow[t]{3}{*}{$\mathrm{P}$ value } & & 0.009 & 0.007 & 0.001 \\
\hline & \multicolumn{4}{|c|}{ rs 10046} \\
\hline & $\mathrm{T} / \mathrm{T}$ & $\mathrm{T} / \mathrm{C}$ & $\mathrm{C} / \mathrm{C}$ & $\mathrm{T} / \mathrm{C}+\mathrm{C} / \mathrm{C}$ \\
\hline \multicolumn{5}{|l|}{ Age onset } \\
\hline$>50 / \leq 50$ & $38 / 62$ & $70 / 115$ & $13 / 36$ & $83 / 151$ \\
\hline OR $(95 \% \mathrm{CI})$ & 1.00 & $1.01(0.61-1.66)$ & $1.70(0.80-3.60)$ & $1.12(0.69-1.81)$ \\
\hline $\mathrm{P}$ value & & 0.978 & 0.165 & 0.659 \\
\hline \multicolumn{5}{|l|}{ Menopause } \\
\hline Post/pre & $48 / 52$ & $68 / 117$ & $15 / 34$ & $83 / 151$ \\
\hline OR $(95 \% \mathrm{CI})$ & 1.00 & $1.59(0.97-2.60)$ & $2.09(1.02-4.31)$ & $1.68(1.04-2.70)$ \\
\hline$P$ value & & 0.065 & 0.043 & 0.031 \\
\hline
\end{tabular}


Table 4. Association analysis of haplotypes with breast cancer patients.

\begin{tabular}{l|c|c|c}
\hline Haplotype & Freq & OR $(95 \% \mathrm{CI})$ & P value \\
\hline CGAGGTC & 0.135 & 1.00 & 0.99 \\
\hline TGAGGTC & 0.105 & $0.99(0.51-1.94)$ & 0.36 \\
\hline CGAGGCC & 0.087 & $0.73(0.37-1.44)$ & 0.51 \\
\hline TGAGGCC & 0.062 & $0.79(0.39-1.59)$ & 0.69 \\
\hline CGAGGCT & 0.054 & $0.87(0.42-1.77)$ & 0.62 \\
\hline CGAGATC & 0.050 & $0.81(0.36-1.83)$ & 0.82 \\
\hline CGAAGTC & 0.050 & $0.90(0.38-2.13)$ & 0.17 \\
\hline CGGGGTC & 0.041 & $2.02(0.74-5.51)$ & 0.24 \\
\hline TGAGATC & 0.032 & $0.51(0.17-3.16)$ & 0.24 \\
\hline CGAGACC & 0.026 & $0.46(0.12-1.57)$ & 0.062 \\
\hline CCAGGTC & 0.023 & $0.15(0.02-1.10)$ & 0.78 \\
\hline TGGGATC & 0.021 & $1.25(0.26-5.97)$ & 0.17 \\
\hline TGAGACT & 0.018 & $2.20(0.71-6.77)$ & $>0.001$ \\
\hline TGGGGTC & 0.017 & $>1000$ & \\
\hline
\end{tabular}

Global haplotype association P value: 0.0025 .

\section{DISCUSSION}

In this case-control study, we investigated associations of hormone-related gene variants and $\mathrm{BC}$ risk in a Chinese population. Of the seven SNPs, CYP19 rs10046, ESR1 rs2046210, and GSTP1 rs1695 were significantly associated with BC risk in this population; one haplotype comprising seven SNPs significantly increased the risk of BC in Chinese women.

CYP19, which converts androgens to estrogens, contributes to variations in circulating hormone levels, and polymorphisms in this gene potentially affect $\mathrm{BC}$ risk (Dunning et al., 2004). Association analysis between rs 10046 and BC in different populations showed inconsistent results (Zhang et al., 2009; Pineda et al., 2013). Karin et al. (Zins et al., 2014) reported that the TT genotype of this polymorphism was associated with an increased BC risk. Our data contradicted two earlier studies in which the CC genotype had a reduced risk of BC. In a stratified analysis, Karin et al. found that rs 10046 may affect BC susceptibility in women below the age of 50 years in an Austrian population. We found that the rs $10046 \mathrm{CC}$ genotype occurred in $16.9 \%$ of women under 50 years of age and $10.7 \%$ in women above 50 years of age in subgroup analysis; however, this difference was not significant. In a stratified analysis by menopausal status, the association between the rs $10046 \mathrm{C}$ allele and $\mathrm{BC}$ was more evident in premenopausal women than postmenopausal women.

Chattopadhyay et al. (2014) previously observed that rs700519 had a significant association with BC risk in North Indian women, which was strongly affected by menopausal status. Sun et al. (2015) also reported that rs700519 is associated with susceptibility to BC among the Han Chinese population. However, Khvostova et al. (2012) and Sangrajrang et al. (2009) found that rs700519 was not associated with BC risk in Siberian and Thai women. Our findings also found no association between rs700519 and BC risk, similar to those of Khvostova and Sangrajrang. However, stratified analysis by age and menopausal status showed the rs700519 $\mathrm{T}$ allele to be more strongly associated with premenopausal women or women under 50 years of age. It suggested that the association between rs 700519 and $\mathrm{BC}$ was evident in premenopausal or women under the age of 50 years.

The $S H B G$ rs6259 influences estrogen bioavailability, but its association with BC is uncertain. In a large study of Chinese women, Zhang et al. (2011) reported that $S H B G$ rs6259 was significantly associated with BC risk in stage I and II combined analyses, in which 
the minor allele (A) produced a reduced risk of disease. However, Clendenen et al. (2013) and Diergaarde et al. (2008) found no association between rs6259 and BC risk, which is in agreement with our findings.

COMT encodes an estrogen-metabolizing enzyme, and the COMT Val108/158Met (rs4680) is thought to reduce enzymatic activity, which has been widely studied as a potential risk factor for BC. Several studies showed no association between rs 4680 and BC risk (20, 2427). We also found no association between the COMT rs 4680 and $\mathrm{BC}$ risk in Chinese women.

The glutathione S-transferase family of proteins is thought to affect conjugation of catechol estrogen quinones; the GSTP1 Val105 allele has been shown to disrupt normal catalytic enzyme activity. Reding et al. (2009) showed that the GSTP1 rs1695 A allele was a protective factor for $\mathrm{BC}$ compared with the $\mathrm{G}$ allele, but several other studies found no association between rs1695 and BC risk (Ramalhinho et al., 2011; Liu et al., 2013). Zhang et al. (2011) reported that the minor allele homozygotes of rs1695 (GG) were associated with an increased risk of developing BC, which is consistent with three other studies in Chinese women (Chang et al., 2006; Lee et al., 2008; Sakoda et al., 2008). Liu et al. (2013) found that GSTP1 rs1695 was associated with BC risk in an Asian population, but not in Caucasians or Africans. In our data, the SNP in rs1695 was found to be associated with an increased BC risk among heterozygote carriers, which is similar to the results of Zhang et al. (2011). The differences in association between rs 1695 and BC among Caucasians, Africans, and Asians could be attributed to the different ethnicities of the various populations.

The SNP rs2046210 is located $180 \mathrm{~kb}$ upstream of the transcription initiation site of the ESR1 first coding exon and was first shown to be associated with increased BC risk by Zheng et al. (2009). Since then, several studies on ESR1 rs2046210 have yielded inconsistent results. Guo et al. (2012) reported that the rs2046210 A allele was significantly associated with $\mathrm{BC}$ risk in a case-control study and then confirmed these findings in a meta-analysis of the overall population. A meta-analysis by Yang et al. (2013) reported that the A allele of rs2046210 was associated with significantly increased BC risk in the overall population. When stratified by ethnicity, this significance was lost in those of African descent, but it was maintained in European and Asian populations. Mizoo et al. (2013) performed a case-control study that associated rs2046210 with higher BC risk in Japanese women. Our results also suggest that rs2046210 T allele carriers (TC and TT genotypes) have a significantly elevated $\mathrm{BC}$ risk compared with those with $\mathrm{CC}$ genotypes. However, we found no evidence that this association was stronger in pre- or postmenopausal women.

The SNP rs9383951 is located in ESR1 intron 5. Long et al. suggested that it was a susceptibility locus for $\mathrm{BC}$, and this allele was associated with decreased $\mathrm{BC}$ risk in East Asians (Long et al., 2012). In our study, rs9383951 was not associated with BC risk in Chinese women.

Haplotype analysis can detect cis-acting causal variants that are potentially associated with disease risk, and the haplotype-specific risks are interesting to consider. In our data, haplotype analyses encompassing all seven SNPs identified 15 haplotypes with frequencies $>0.01$. A haplotype with frequency 0.017 was associated with extremely increased $\mathrm{BC}$ risk (TGGGGTC; OR: >1000) compared with the reference haplotype (CGAGGTC, 13.5\%). Although not all seven SNPs in hormone-related genes are associated with BC risk, the haplotype TGGGGTC composed of seven SNPs significantly increased the risk of BC.

In summary, we reported associations between BC risk and ESR1 rs2046210, GSTP1 rs1695, and CYP19 rs10046 SNPs and identified a haplotype TGGGGTC that was associated with a highly increased risk of $\mathrm{BC}$ in Chinese women. These findings suggest that the ESRI, 
GSTP1, and CYP19 polymorphisms are likely to play an important role in BC among Chinese women, and the TGGGGTC haplotype could be a genetic marker for $\mathrm{BC}$ risk.

\section{ACKNOWLEDGMENTS}

Research supported by the National Natural Science Foundation (\#81372210), the Talents Project of Zhejiang Province Medical Health Platform (\#2011RCA011), and the Medical and Health Science Project of Zhejiang Province (\#2015103934).

\section{REFERENCES}

Chang TW, Wang SM, Guo YL, Tsai PC, et al. (2006). Glutathione S-transferase polymorphisms associated with risk of breast cancer in southern Taiwan. Breast 15: 754-761. http://dx.doi.org/10.1016/j.breast.2006.03.008

Chattopadhyay S, Siddiqui S, Akhtar MS, Najm MZ, et al. (2014). Genetic polymorphisms of ESR1, ESR2, CYP17A1, and CYP19A1 and the risk of breast cancer: a case control study from North India. Tumour Biol. 35: 4517-4527. http://dx.doi.org/10.1007/s13277-013-1594-1

Chen WY (2008). Exogenous and endogenous hormones and breast cancer. Best Pract. Res. Clin. Endocrinol. Metab. 22: 573-585. http://dx.doi.org/10.1016/j.beem.2008.08.001

Clendenen T, Zeleniuch-Jacquotte A, Wirgin I, Koenig KL, et al. (2013). Genetic variants in hormone-related genes and risk of breast cancer. PLoS One 8: e69367. http://dx.doi.org/10.1371/journal.pone.0069367

Dawling S, Roodi N, Mernaugh RL, Wang X, et al. (2001). Catechol-O-methyltransferase (COMT)-mediated metabolism of catechol estrogens: comparison of wild-type and variant COMT isoforms. Cancer Res. 61: 6716-6722.

Diergaarde B, Potter JD, Jupe ER, Manjeshwar S, et al. (2008). Polymorphisms in genes involved in sex hormone metabolism, estrogen plus progestin hormone therapy use, and risk of postmenopausal breast cancer. Cancer Epidemiol. Biomarkers Prev. 17: 1751-1759. http://dx.doi.org/10.1158/1055-9965.EPI-08-0168

Dunning AM, Dowsett M, Healey CS, Tee L, et al. (2004). Polymorphisms associated with circulating sex hormone levels in postmenopausal women. J. Natl. Cancer Inst. 96: 936-945. http://dx.doi.org/10.1093/jnci/djh167.

Guo H, Ming J, Liu C, Li Z, et al. (2012). A common polymorphism near the ESR1 gene is associated with risk of breast cancer: evidence from a case-control study and a meta-analysis. PLoS One 7: e52445. http://dx.doi.org/10.1371/ journal.pone. 0052445

Haiman CA, Riley SE, Freedman ML, Setiawan VW, et al. (2005). Common genetic variation in the sex steroid hormonebinding globulin (SHBG) gene and circulating shbg levels among postmenopausal women: the Multiethnic Cohort. J. Clin. Endocrinol. Metab. 90: 2198-2204. http://dx.doi.org/10.1210/jc.2004-1417

Jurinke C, van den Boom D, Cantor CR and Köster H (2002). Automated genotyping using the DNA MassArray technology. Methods Mol. Biol. 187: 179-192.

Kaaks R, Rinaldi S, Key TJ, Berrino F, et al. (2005). Postmenopausal serum androgens, oestrogens and breast cancer risk: the European prospective investigation into cancer and nutrition. Endocr. Relat. Cancer 12: 1071-1082. http://dx.doi. org $/ 10.1677 /$ erc. 1.01038

Key T, Appleby P, Barnes I and Reeves G; Endogenous Hormones and Breast Cancer Collaborative Group (2002). Endogenous sex hormones and breast cancer in postmenopausal women: reanalysis of nine prospective studies. $J$. Natl. Cancer Inst. 94: 606-616. http://dx.doi.org/10.1093/jnci/94.8.606

Key TJ, Appleby PN, Reeves GK, Travis RC, et al.; Endogenous Hormones and Breast Cancer Collaborative Group (2015). Steroid hormone measurements from different types of assays in relation to body mass index and breast cancer risk in postmenopausal women: Reanalysis of eighteen prospective studies. Steroids 99 (Pt A): 49-55. http:// dx.doi.org/10.1016/j.steroids.2014.09.001

Khvostova EP, Pustylnyak VO and Gulyaeva LF (2012). Genetic polymorphism of estrogen metabolizing enzymes in Siberian women with breast cancer. Genet. Test. Mol. Biomarkers 16: 167-173. http://dx.doi.org/10.1089/ gtmb.2011.0131

Lee SA, Fowke JH, Lu W, Ye C, et al. (2008). Cruciferous vegetables, the GSTP1 Ile105Val genetic polymorphism, and breast cancer risk. Am. J. Clin. Nutr. 87: 753-760.

Liu JJ, Liu JL, Zhang X, Xie L, et al. (2013). A meta-analysis of the association of glutathione S-transferase P1 gene polymorphism with the susceptibility of breast cancer. Mol. Biol. Rep. 40: 3203-3212. http://dx.doi.org/10.1007/ $\underline{\text { s11033-012-2396-Z }}$ 
Long J, Cai Q, Sung H, Shi J, et al. (2012). Genome-wide association study in east Asians identifies novel susceptibility loci for breast cancer. PLoS Genet. 8: e1002532. http://dx.doi.org/10.1371/journal.pgen.1002532

Lukanova A, Lundin E, Micheli A, Arslan A, et al. (2004). Circulating levels of sex steroid hormones and risk of endometrial cancer in postmenopausal women. Int. J. Cancer 108: 425-432. http://dx.doi.org/10.1002/ijc.11529

Missmer SA, Eliassen AH, Barbieri RL and Hankinson SE (2004). Endogenous estrogen, androgen, and progesterone concentrations and breast cancer risk among postmenopausal women. J. Natl. Cancer Inst. 96: 1856-1865. http:// dx.doi.org/10.1093/jnci/djh336

Mizoo T, Taira N, Nishiyama K, Nogami T, et al. (2013). Effects of lifestyle and single nucleotide polymorphisms on breast cancer risk: a case-control study in Japanese women. BMC Cancer 13: 565. http://dx.doi.org/10.1186/14712407-13-565

Pike MC, Krailo MD, Henderson BE, Casagrande JT, et al. (1983). 'Hormonal' risk factors, 'breast tissue age' and the age-incidence of breast cancer. Nature 303: 767-770. http://dx.doi.org/10.1038/303767a0

Pineda B, García-Pérez MA, Cano A, Lluch A, et al. (2013). Associations between aromatase CYP19 rs10046 polymorphism and breast cancer risk: from a case-control to a meta-analysis of 20,098 subjects. PLoS One 8: e53902. http://dx.doi.org/10.1371/journal.pone.0053902

Ramalhinho AC, Fonseca-Moutinho JA and Breitenfeld L (2011). Glutathione S-transferase M1, T1, and P1 genotypes and breast cancer risk: a study in a Portuguese population. Mol. Cell. Biochem. 355: 265-271. http://dx.doi.org/10.1007/ s11010-011-0863-9

Reding KW, Weiss NS, Chen C, Li CI, et al. (2009). Genetic polymorphisms in the catechol estrogen metabolism pathway and breast cancer risk. Cancer Epidemiol. Biomarkers Prev. 18: 1461-1467.

Sakoda LC, Blackston CR, Xue K, Doherty JA, et al. (2008). Glutathione S-transferase M1 and P1 polymorphisms and risk of breast cancer and fibrocystic breast conditions in Chinese women. Breast Cancer Res. Treat. 109: 143-155. http://dx.doi.org/10.1007/s10549-007-9633-5

Sangrajrang S, Sato Y, Sakamoto H, Ohnami S, et al. (2009). Genetic polymorphisms of estrogen metabolizing enzyme and breast cancer risk in Thai women. Int. J. Cancer 125: 837-843. http://dx.doi.org/10.1002/ijc.24434

Solé X, Guinó E, Valls J, Iniesta R, et al. (2006). SNPStats: a web tool for the analysis of association studies. Bioinformatics 22: 1928-1929. http://dx.doi.org/10.1093/bioinformatics/btl268

Sun MY, Du HY, Zhu AN, Liang HY, et al. (2015). Genetic polymorphisms in estrogen-related genes and the risk of breast cancer among Han Chinese women. Int. J. Mol. Sci. 16: 4121-4135. http://dx.doi.org/10.3390/ijms16024121

Yang Z, Shen J, Cao Z and Wang B (2013). Association between a novel polymorphism (rs2046210) of the 6q25.1 locus and breast cancer risk. Breast Cancer Res. Treat. 139: 267-275. http://dx.doi.org/10.1007/s10549-013-2494-1

Zhang B, Beeghly-Fadiel A, Lu W, Cai Q, et al. (2011). Evaluation of functional genetic variants for breast cancer risk: results from the Shanghai breast cancer study. Am. J. Epidemiol. 173: 1159-1170. http://dx.doi.org/10.1093/aje/ $\underline{\mathrm{kwr} 004}$

Zhang L, Gu L, Qian B, Hao X, et al. (2009). Association of genetic polymorphisms of ER-alpha and the estradiolsynthesizing enzyme genes CYP17 and CYP19 with breast cancer risk in Chinese women. Breast Cancer Res. Treat. 114: 327-338. http://dx.doi.org/10.1007/s10549-008-9998-0

Zheng W, Long J, Gao YT, Li C, et al. (2009). Genome-wide association study identifies a new breast cancer susceptibility locus at 6q25.1. Nat. Genet. 41: 324-328. http://dx.doi.org/10.1038/ng.318

Zimniak P, Nanduri B, Pikuła S, Bandorowicz-Pikuła J, et al. (1994). Naturally occurring human glutathione S-transferase GSTP1-1 isoforms with isoleucine and valine in position 104 differ in enzymic properties. Eur. J. Biochem. 224: 893-899. http://dx.doi.org/10.1111/j.1432-1033.1994.00893.x

Zins K, Mogg M, Schneeberger C, Abraham D, et al. (2014). Analysis of the rs10046 polymorphism of aromatase (CYP19) in premenopausal onset of human breast cancer. Int. J. Mol. Sci. 15: 712-724. http://dx.doi.org/10.3390/ ijms 15010712 